\title{
LA REPARACIÓN DEL DAÑO MORAL DERIVADO DEL INCUMPLIMIENTO CONTRACTUAL. TENDENCIA EN LA RECIENTE JURISPRUDENCIA NACIONAL Y ESPAÑOLA
}

\author{
THE COMPENSATION OF NON MATERIAL DAMAGE FROM \\ CONTRACTUAL DEFAULT. RECENT TRENDS IN CHILEAN AND \\ SPANISH JURISPRUDENCE
}

Romy Grace Rutherford Parentti ${ }^{1-2}$

\begin{abstract}
RESUMEN: El presente artículo tiene como finalidad hacer un análisis comparativo que revele el estado actual de la cuestión relativa al daño moral derivado del incumplimiento contractual, poniendo de relieve la actual jurisprudencia emitida por el máximo tribunal nacional, en relación con los dictámenes pronunciados por el Tribunal Supremo español, tomando como referencia los últimos cinco años.
\end{abstract}

Palabras clave: Incumplimiento de contrato, daño moral, indemnización, jurisprudencia.

ABSTRACT: The article presented has the finality of making a comparative analysis that reveals the actual state of the question of the moral damage resulting from the breach of contract in the jurisprudence of the highest national court, in relation to the opinions delivered by the Spanish Supreme Court, with reference to the last five years.

Key words: Breach of contract, moral damage, compensation, jurisprudence.

\section{INTRODUCCIÓN}

Ardua ha sido la tarea por intentar resolver el dilema que se presenta cuando nos enfrentamos al incumplimiento, cumplimiento tardío o defectuoso de un contrato, particularmente en lo que se refiere a la procedencia o no de la reparación del daño moral. El debate no ha sido menor, pero el desarrollo de las ideas en tal sentido y la consiguiente evolución que con ocasión de aquello ha devenido, sin lugar a dudas, ha valido el camino que ha sido necesario recorrer.

Sabemos que en un sistema que carece de normas que regulen de forma expresa la pertinencia o la inadecuación, en su caso, de una reparación como la que se indica, cobran notabilidad tanto la doctrina como la jurisprudencia, esta última por ser finalmente la llamada a resolver los conflictos de relevancia jurídica que sobre el particular se presenten ${ }^{3} ; \mathrm{y}$

\footnotetext{
1 Abogada, Licenciada en Derecho Universidad Gabriela Mistral. Alumna Programa de Doctorado en Derecho, Pontificia Universidad Católica de Chile. Correo electrónico rgrutherford@uc.cl.

2 La autora agradece los importantes aportes efectuados por la Profesora Dr ${ }^{\mathrm{a}}$. Carmen Domínguez Hidalgo al presente trabajo.

3 Sobre el tema y en relación con la labor de la jurisprudencia señala el profesor Domínguez Águila en el prólogo del libro de Díez Schwerter (1997) p. 12: "es necesario destacar muchas sentencias que, guiándose más por el buen criterio que por fundamentos doctrinarios, hacen intentos por responder a nuevas realidades en la necesidad de la reparación".
} 
la primera, por ser a quien toca la labor de ilustrar a los jurisdicentes en aras de revelarles una solución que se identifique con el sentido armónico que debe presentar el ordenamiento jurídico, debidamente ajustada a su espíritu y a las corrientes modernas.

En este contexto, diversos han sido los postulados y las justificaciones que se han formulado por los tratadistas en su intento por convencer sobre la procedencia de la reparación del daño moral derivado del contrato. En tal empeño se han alineado diversos autores nacionales ${ }^{4}$ como extranjeros $^{5}$, resultando ser en definitiva la posición que más adeptos recoge en la actualidad sobreponiéndose a la tesis contraria ${ }^{6}$. Quienes propugnan esta tendencia encuentran su fundamentación sustancialmente en una ausencia de la patrimonialidad de la prestación; en los principios generales del derecho; en una adecuada reinterpretación de las normas que reglan las obligaciones; en un ajuste terminológico de la conceptualización de daño emergente y, por último, en razones de justicia.

Si hurgamos en el sistema chileno y en el español hemos de encontrar grandes similitudes, tanto en cuanto a los obstáculos que han debido soslayarse para concluir en la procedencia del daño moral en esta materia, como también en la consecuente evolución que ha devenido producto del reencauzamiento admitido a su respecto, a pesar de encontrarnos un paso atrás en este recorrido.

El presente trabajo no busca, como es fácil comprender, resolver todos los aspectos relacionados con el daño moral derivado del contrato, empero sí aspira a presentar al lector un análisis capaz de exhibir cuál ha sido la posición de la jurisprudencia nacional, representada esta última por los dictámenes de la Primera Sala (Civil) de la Corte Supre$\mathrm{ma}^{7}$, en paralelo con los veredictos pronunciados por el Tribunal Supremo español. Para ello tomaremos en consideración exclusivamente los últimos cinco años, esto es, el periodo comprendido entre 2007 y $2012^{8}$.

\footnotetext{
4 Baltierra (1956); Fueyo (1965) p. 72 y 103; Tomasello (1969); Fueyo (1972) p. 26; Domínguez Águila (2000), Id. (2005); Domínguez Águila-Domínguez Benavente (1993), ID. (1994); Illanes (1994); Court (1998) pp. 286 y 287; Domínguez Hidalgo (1998) p. 50; Aedo (2001); Abeliuk (2003) posición actual; Corral (2003); Rodríguez (2003) pp. 244, 245 y 258, 263 (aunque solo tratándose de daño moral impropio); Fueyo (2004) pp. 384 y ss.; Jana-Tapia (2004) p. 585; Molinari (2004); Ramos (2004) pp. 288 y ss.; Cárdenas (2006) p. 192; Barrientos (2007) p. 16; Tapia (2007) p. 378; Domínguez Hidalgo (2000); Barrientos (2010) p. 165; Corral (2010) p. 8; ID. (2010) Contratos y daños por incumplimiento; Gandarillas (2011); Pizarro (2011) p. 309; Salinas (2011).

5 Álvarez Vigaray (1966); Carrasco Perera (1989); Cristóbal Montes (1990); Díez-Picazo (1999) p. 329, quien sostiene la posibilidad de indemnizar el daño moral por incumplimiento derivado del contrato solo en aquellos casos en que la prestación contractual comprometida por el incumplidor afecta derechos subjetivos de la personalidad del acreedor.

6 Postulada entre otros en Chile por Butrón (1920) p. 39; Barros Errázuriz (1932) p. 89; Alessandri (1943) p. 45; Gatica (1959) p. 144; Vodanovic (1970) p. 217; Somarriva (1984) p. 69; De la Maza (1988) pp. 29 ss.; Abeliuk (1993) p. 760 (en nueva publicación, cuarta edición, cambia posición diciendo que sí procede, p. 790); Vergara (2000) p. 70; y en la doctrina española por Valverde-Valverde (1937); De Diego (1959); Puig Peña (1976); Castán Tobeñas (1993).

7 Las sentencias que se citan en este trabajo han sido seleccionadas de la base de jurisprudencia que se encuentra en el sitio web oficial del Poder Judicial nacional (www.poderjudicial.cl).

8 La razón para fijar este periodo es doble: porque es un término razonable para marcar líneas de evolución o confirmación de criterios y porque ya existe un análisis que incluye sentencias dictadas por la Corte Suprema entre los años 2002 a 2007: Barrrientos (2010) pp. 163-170.
} 


\section{LA DOCTRINA FRENTE A LA PATRIMONIALIDAD DE LA PRESTACIÓN VERSUS LA EXTRAPATRIMONIALIDAD DEL DAÑO MORAL}

Si bien la procedencia del daño moral en materia extracontractual ya se encuentra resuelta y zanjada de forma positiva en los diversos sistemas jurídicos, lo cierto es que conducido este asunto al plano contractual la respuesta ha presentando vacilaciones, las que han ido desde el rechazo total hasta su acogimiento generalizado ${ }^{9}$, aun cuando no unánime.

Pese a que en el ámbito nacional no se formuló el debate que sí se presentara en el derecho comparado, en relación con el que se ha estimado el primer gran inconveniente que han debido enfrentar quienes sustentan la procedencia del daño moral en el ámbito antes indicado, cual es, la patrimonialidad de la obligación emanada del contrato, lo cierto es que no podemos omitir su examen por tratarse del factor determinante en los países que han ido a la vanguardia en esta materia.

En este sentido debe anotarse que el basamento sobre el cual parte de la doctrina construye tal obstáculo se sitúa en una aparente incompatibilidad entre el carácter económico de la prestación contractual y la naturaleza extrapatrimonial del daño que se pretende resarcir. Así ha sido menester responder a quienes, trazando la opinión opuesta, señalan que la prestación debe ser susceptible en sí misma de apreciación pecuniaria; que debe presentar para el acreedor una ventaja apreciable en dinero y, que el simple interés moral o de afección del acreedor no es suficiente para condenar al deudor a daños y perjuicios, porque esta indemnización, a su entender, representa el interés que tiene el acreedor en la ejecución de la obligación y, si aquel no es apreciable en dinero, tampoco lo puede ser la indemnización de daños y perjuicios ${ }^{10}$, postulado este que proviene de lo expresado por PothieR ${ }^{11}$, a partir de antecedentes que sitúa en el Derecho Romano ${ }^{12}$ y que resultó ser la opinión compartida por otros autores de la época, luego por los codificadores y más tarde por quienes interpretan el articulado $^{13}$.

La inclinación antes dicha, que representa el planteamiento clásico, encuentra ciertamente sus raíces en la noción de reparación que tienen dichos escritores, la cual solo se entiende respecto de un perjuicio de naturaleza patrimonial. Olvidan sin embargo que "...la reparación en dinero es siempre una compensación y nunca el cumplimiento exacto de la obligación. La clave para resolver el problema está en el contenido que se le asigna a la idea de compensación"14. $\mathrm{Si}$ bien ha de perseguirse, idealmente, la equivalencia precisa de la reparación, lo cierto es que

9 Domínguez Hidalgo (2006).

10 Tomasello (1969) p. 103; Aedo (2001) p. 445.

11 Pothier (2007) p. 112: “... un hecho para ser materia de una obligación civil debe ser uno por el cual aquel respecto de quién será contratado tenga un interés apreciable a precio de dinero".

12 Domat alude al fragmento de D. 9,2,33 pr. (Paul. 2 ad Plat.) para sostener que el Derecho Romano era contrario al resarcimiento del daño moral, asumiendo, en palabras de la profesora Domínguez Hidalgo (2000) p. 171, un error al prescindir de los textos del Bajo Imperio que demuestran que al menos en cierta época del Derecho Romano sí reconoce un principio de reparación del daño moral derivado de contrato; equivocación que fue transmitida, entre otros, a POTHIER quien exige un interés pecuniario por parte del acreedor como presupuesto necesario para la reparación de los perjuicios.

13 Rodríguez Guitián (2008) p. 146.

14 Domínguez Hidalgo (2000) p. 158. 
aquello no es posible e incluso muy difícil aun tratándose de daños patrimoniales, de suerte que la indemnización debe entenderse “...como una compensación que se otorga al perjudicado para resarcirle, en la medida de lo posible, tales perjuicios..." 15 . De esta forma, corresponde dejar atrás la idea de reparación que se identifica con el restablecimiento pleno en términos de alcanzar una supresión total del perjuicio, toda vez que solo puede aspirarse, con la asignación de una suma de dinero, a las satisfacciones que la víctima o acreedor estimen del caso ${ }^{16}$.

Consecuencialmente, si le otorgamos a la reparación el sentido antes dicho, esto es, en términos amplios, habremos salvado el obstáculo que advierten quienes plantean la improcedencia del daño moral derivado del contrato y, de paso, evitaremos la odiosa e injustificada distinción que pudiera hacerse entre esta, que atiende a la infracción de un deber específico -la obligación contractual-y la reparación del mismo daño tratándose de la responsabilidad aquiliana, que mira al cumplimiento de un deber genérico -de respeto a los demás-, en donde este tema se encuentra superado desde hace mucho.

Es menester, para obtener la justa medida, conciliar la idea de lo patrimonial con la de lo extrapatrimonial, de forma tal que acercando ambos aspectos se logre la debida tutela de la persona y a sus intereses, sean estos pecuniarios o no y, como consecuencia de ello, se conduzca a un concepto más amplio de obligación, donde se acepte que la misma puede o no estar constituida por una prestación de índole patrimonial ${ }^{17}$. Lo anterior es absolutamente posible, más tratándose de un ordenamiento como el nuestro o el español, en que no se exige en forma expresa la patrimonialidad de la prestación ni tampoco del interés del acreedor en la obligación ${ }^{18}$.

\section{LAS NORMAS LEGALES VISTAS COMO LÍMITES A LA REPARACIÓN DEL DAÑO MORAL DERIVADO DEL CONTRATO}

Corresponde a continuación abocarnos al segundo escollo que advierte la doctrina para superar el tema, esto es, el referido al contenido normativo, que a los ojos de algunos justifica el rechazo de cualquier posible resarcimiento del daño extrapatrimonial que se hubiera causado en el ámbito contractual ${ }^{19}$. No obstante encontrarse salvada esta rémora en la mayoría de los ordenamientos jurídicos, es menester recurrir a su análisis desde que ha sido relevante en las legislaciones objeto de estudio, las cuales carecen de norma expresa que resuelva el asunto ${ }^{20}$. En efecto, el reparo planteado, que viene de la mano con la con-

15 Domínguez Hidalgo (2000) p. 161; Id. (2011) p. 664.

16 Domínguez Hidalgo (2000) p. 162. Díez-Picazo (2008) p. 96. En palabras de Díez Schwerter (1997) pp. 247 ss. En el mismo sentido Domínguez Águila (1990) p.129; Fueyo (1990) pp. 110 y 111; p. 175; Rodríguez Grez (2003) p. 239; Barrientos (2008) pp. 100 ss.

17 Domínguez Hidalgo (2000) p. 226.

18 Se señala que los artículos 1460 y 1461 del Código Civil chileno no exige un contenido económico al objeto de la obligación. Véase Tomasello (1969) p. 136; León (1983) p. 4; Aedo (2001) p. 451.

19 Véase supra, n. 4.

20 El sistema francés, careciendo de norma expresa, ha desarrollado la reparación del daño moral derivado del contrato en términos equivalentes a los extracontractuales. Por su parte la legislación argentina recoge expresamente la reparación de los daños morales en esta materia en el artículo 552 del Código Civil. Véase Parellada (2006) p. 161; Mayo-Prevot (2007) p. 334; Miquel (2008) p. 215. 
cepción patrimonialista de la obligación, pretende denegar la reparación del daño moral, en primer término, y de manera central, fundándose en el caso chileno en lo que prevé el artículo 1556 del Código Civil. Dicen estos autores ${ }^{21}$ que en la norma en comento no cabe el daño moral, toda vez que se refiere exclusivamente a la disminución efectiva del patrimonio y de la ganancia que se ha dejado de percibir, además de detentar ambos conceptos, «daño emergente» y «lucro cesante», un contenido netamente pecuniario ${ }^{22}$. Frente a este argumento contesta Fueyo $^{23}$ que el precepto citado no niega la reparación del daño moral así como ninguna norma lo hace ${ }^{24}$. Luego, agrega, esta división entre daño emergente y lucro cesante no puede excluir la reparación amplia, pues esta clasificación solo atiende a la actualidad o futuridad del perjuicio en cuanto a su ocurrencia ${ }^{25}$.

Con todo, la ley no ha prohibido invocar el daño moral en un estatuto resarcitorio diverso del extracontractual. Aun más, precisamente la reinterpretación de la antedicha disposición ha servido de sustento tanto a la doctrina como a la jurisprudencia para argumentar en favor del daño moral derivado del contrato $^{26}$, en el entendido que la referencia al «daño emergente» allí contenida, y cuya definición no ha sido dada por el legislador, comprende no solo el daño patrimonial sino también el extrapatrimonial. De esta forma se descarta la inteligencia exegética de la norma en comento ${ }^{27}$.

Por su parte, el artículo $1106^{28}$ del Código Civil español al referirse a los daños y perjuicios indemnizables alude a términos más generales, como son la "pérdida sufrida» o la "ganancia dejada de obtener", circunstancia esta que permite que aquellos conceptos sean entendidos no exclusivamente referidos al aspecto material de los perjuicios. Empero, de todos modos se utilizó esta norma como sustento para desestimar la procedencia del daño moral derivado del contrato, con los mismos argumentos que se han referido al hacer mención al sistema nacional, esto es, que el legislador en forma expresa dispuso que solo era pertinente la reparación del lucro cesante y del daño emergente ${ }^{29}$.

21 Alessandri (1943); Gatica (1956); Abeliuk (1993).

22 Abeluik (1993).

23 Fueyo (2004) p. 385.

24 En el mismo sentido, Illanes (1994) p. 12; Aedo (2001) p. 454; Jana-Tapia (2004) p.180; Molinari (2004) p. 128; Ramos (2004) p. 391; Domínguez Hidalgo (2006) p. 309; Barrientos (2007) p. 16.

25 Así lo ha entendido la jurisprudencia dictada a partir de la sentencia de 20 de octubre de 1994 pronunciada por la Corte Suprema, en Revista de Derecho y Jurisprudencia, T. 91, sección 1a, p. 101.

26 Domínguez Águila (2001) p. 156.

27 JANA-TAPIA (2004) p.189; sostienen que es discutible esta postura desde que existe una larga tradición en el derecho comparado y en el nacional que atribuye al daño emergente una significación estrictamente vinculada a la pérdida patrimonial actual.

28 Artículo 1106 Código Civil español: "La indemnización de daños y perjuicios comprende no solo el valor de la pérdida que hayan sufrido, sino también el de la ganancia que haya dejado de obtener el acreedor, salvas las disposiciones contenidas en los artículos siguientes".

29 Álvarez Vigaray (1966) p. 99. 
A su vez, los artículos $1101^{30}$ y 1106 se ha dicho, no distinguen entre los perjuicios cuya indemnización ordena ${ }^{31}$ ni prohíbe el resarcimiento no patrimonial ${ }^{32}$. Luego, debe tenerse presente que ciertamente los redactores de los códigos nacional y español no tuvieron en mente la indemnización del daño moral y solo pensaron en el daño pecuniario ${ }^{33}$.

En otro plano y abordando el tópico en examen al amparo de la norma contenida en el artículo 1558 del Código Civil ${ }^{34}$ no podríamos sino colegir -a partir de la referencia que a "todo daño" efectúa ese precepto- que la nebulosa que ha rodeado la procedencia del resarcimiento del detrimento no patrimonial derivado del contrato, se encuentra resuelta ${ }^{35}$. A idéntica conclusión llegamos si observamos en artículo $1107^{36}$ del Código Civil español que se encuentra redactado en términos similares, desde que en ambos casos debemos incluir dentro de esa expresión al daño moral ${ }^{37}$.

Si bien también se ha argüido que al confrontar el contenido de las normas que regulan la responsabilidad aquiliana (artículos $2314^{38}$ y siguientes) con las contractuales se evidencia un tratamiento distinto, desde que en las primeras se hace mención expresa al resarcimiento de "todo daño" y en las segundas ello se omite, resulta axiomático concluir, a partir de un examen metódico del ordenamiento jurídico, que no hay razón ni precepto que impida tal reparación al margen del campo extracontractual ${ }^{39}$.

La preocupación moderna está centrada en la protección absoluta de la persona tanto en su esfera personal como económica, de suerte que la lectura que se haga del conjunto normativo debe serlo a la luz de esa tutela, que encuentra amparo en la Carta Fundamental chilena -artículo 19 Nros. 1 y 4 - como igualmente sucede en la española de 1978. Solo de esta forma hemos de reformular el concepto de daño moral en términos tales que nos permitan su debido resguardo.

30 "Quedan sujetos a la indemnización de los daños y perjuicios causados los que en el cumplimiento de sus obligaciones incurrieren en dolo, negligencia o morosidad, y los que de cualquier modo contravinieren al tenor de aquella”.

31 Yzquierdo Tolsada (1993) p. 230.

32 Solé Feliú (2009) p. 21, citando a Carrasco Perera.

33 Rodríguez Guitián (2008) pp. 145 ss.; Tomasello (1969) pp. 162 ss.; Domínguez Hidalgo (1998) p. 49; ID. (2000) p. 348.

34 La norma está tomada del artículo 1150 del Código Civil francés. Domínguez Águila (2010) p. 18: "Los comentaristas atribuyen históricamente la regla a precedentes romanos y a los glosadores; pero más bien aparece en Charles Dumoulin y luego en Jean Domat y claramente en Robert J. Pothier, quien inspira al Código francés y al nuestro por tanto".

35 En este sentido Barrientos (2010) p. 165.

36 "Los daños y perjuicios de que responde el deudor de buena fe son los previstos o que se hayan podido prever al tiempo de constituirse la obligación y que sean consecuencia necesaria de su falta de cumplimiento. En caso de dolo responderá el deudor de todos los que conocidamente se deriven de la falta de cumplimiento de la obligación".

37 Barrientos (2007) p. 359.

38 En el mismo tenor está redactado el artículo 1902 del Código español: "El que por acción u omisión causa daño a otro, interviniendo dolo o culpa, está obligado a reparar el daño causado".

$39 \mathrm{Al}$ efecto debe considerarse los artículos 1562, 1533, 1853, 1930 y 1949; existiendo incluso disposiciones que la permiten en el ámbito familiar y de las convenciones en su caso -artículos 544 en relación con el 539 y 1544 del Código Civil-, más cuando la coherencia con la lógica y la justicia de la reparación integral solo permiten arribar a una conclusión que acepte la reparación que se cuestiona. 
En armonía con lo expresado cobra relevancia el argumento que aduce que una vez admitido el daño no patrimonial en el ámbito extracontractual se carece de motivos que justifiquen su rechazo en sede contractual ${ }^{40}$, fundamento que se sustenta en la igualdad y la equidad.

Comoquiera y en idéntica dirección encontramos los principios generales del derecho que, como herramientas válidas, permiten solucionar la disyuntiva planteada. Entonces, la reparación de los daños causados a otro como principio esencial del vigente ordenamiento jurídico, la buena fe y la equidad parecen descollar al momento de pronunciarse sobre el asunto sometido a nuestro análisis ${ }^{41}$.

Asentado que ha quedado el sustrato de la problemática que ha debido ser superada, compelida por la fuerza de la razón y del ordenamiento jurídico, corresponde a continuación examinar los dictámenes emitidos por los Tribunales Superiores de justicia sobre la materia.

\section{ANÁLISIS DE LA JURISPRUDENCIA DE LA CORTE SUPREMA CHILENA}

En la sentencia dictada el 11 de junio de $2012^{42}$, se puede apreciar la posición actual de nuestra jurisprudencia en torno al resarcimiento del daño moral en materia de infracción contractual. En los sucesivos considerandos de la resolución comentada se van afirmando una serie de principios y fundamentos que dan lugar al tipo de reparación al que nos referi$\operatorname{mos}^{43}$ : (a) Que el debate en torno a su procedencia se ha visto mayoritariamente superado, por la misma Corte Suprema, por amplios sectores de la doctrina y por la generalidad de la jurisprudencia. De allí, entonces, afirma que el daño moral en el citado régimen ha de en-

40 Álvarez Vigaray (1966); Castán Tobeñas (1993); Yzquierdo Tolsada (1993).

41 En este sentido Hernández Gil, Castán Tobeñas, Lacruz Berdejo; R. de Ángel Yaguez, L. Pascual Estevill y SANTos Briz aluden al rango de principio general del derecho que alcanza la compensación del daño moral, citados en Domínguez Águila - Domínguez Benavente (1994) p.158. Asimismo Carrasco Perera (1989) pp. 699 y ss.

42 Corte Suprema, 11 de junio de 2012, Nº de Ingreso 7974-2009.

43 Previamente la Corte Suprema había ya resuelto a favor de la procedencia de la indemnización en estos casos, aun cuando no con todos los fundamentos que aquí se esgrimen: Corte Suprema, 30 de marzo de 2012, $\mathrm{N}^{\circ}$ de Ingreso 2560-2011; Corte Suprema, 25 de marzo de 2008, $\mathrm{N}^{\circ}$ de Ingreso 4.931-2006; 25 de septiembre de 2008, $\mathrm{N}^{\circ}$ de Ingreso 59-2007; 29 de octubre de 2008, $\mathrm{N}^{\circ}$ de Ingreso 4.727-2007; 7 de enero de 2009, $\mathrm{N}^{\circ}$ de Ingreso 5.814-2007; 26 de enero de 2009, $\mathrm{N}^{\circ}$ de Ingreso 5.329-2007; 7 de septiembre de 2009, $\mathrm{N}^{\circ}$ de Ingreso 1.879-2008; 5 de octubre de 2009, $\mathrm{N}^{\circ}$ de Ingreso 1.922-2008; 26 de octubre de 2009, $\mathrm{N}^{\circ}$ de Ingreso 1.722-2008; 13 de marzo de 2007, $\mathrm{N}^{\circ}$ de Ingreso 7.118-2007; 11 de abril de 2007, $\mathrm{N}^{\circ}$ de Ingreso 3.291-2005, 25 de mayo de 2010, $\mathrm{N}^{\circ}$ de Ingreso 5.849-2008; 4 de abril de 2011, $\mathrm{N}^{\circ}$ de Ingreso 7.270-2009; 19 de octubre de 2010, $\mathrm{N}^{\circ}$ de Ingreso 7.076-2010: "Que la doctrina de los autores, actualmente en boga, asume también el carácter comprensivo del daño moral como rubro indemnizable a causa del incumplimiento contractual; evidencia de lo cual es lo afirmado por don Fernando Fueyo en la obra Instituciones del Derecho Civil Moderno (página 69)". Continúa argumentando la sentencia en comento: "En el mismo sentido se expresa doña Carmen Domínguez Hidalgo, al sostener que "el legislador no ha distinguido entre los daños materiales y los morales, sino que se ha limitado a referirse al daño emergente y donde no distingue el legislador no es lícito al intérprete hacerlo. Reafirma, además, esta interpretación la definición de la voz «emergente» por el diccionario antes aludido y según el cual se dice que algo es emergente cuando nace de otra cosa. De forma que cuando el legislador empleó el adjetivo "emergente» para calificar al sustantivo "daño", estaba queriendo decir, simplemente, que este daño provenía de no haberse cumplido la obligación, de haberse cumplido imperfectamente o de haberse retardado el cumplimiento (El Daño Moral. Editorial Jurídica de Chile. Tomo I, página 346)" (Considerando Undécimo). 
tenderse como un principio general del sistema de responsabilidad civil de nuestro país; (b) Que nuestro ordenamiento no distingue entre daños de naturaleza moral y patrimonial, por lo tanto, no cabe al intérprete distinguir entre ambos a objeto de descartar una de estas categorías allí donde el legislador no lo ha hecho; (c) Tampoco se ha dicho que la indemnización del daño o perjuicio material, excluye la incidencia y reparación del daño moral o, por fin, que uno merezca tutela jurídica por sobre el otro; (d) Que es dable aplicar el principio de equidad que, junto al de buena fe en la ejecución de los contratos, rigen en nuestro sistema jurídico y al amparo de ambos resulta inadmisible la idea de permitir que un perjuicio injusto quede sin reparación o que un contratante obtenga provecho del negocio celebrado provocando un desmedro, no contemplado, en los intereses patrimoniales o extrapatrimoniales del otro; (e) Que la ley no ha prohibido que la indemnización por daño moral pueda invocarse fuera del ámbito del estatuto aquiliano, por el contrario, el artículo 544, en relación con los artículos 539 y el 1544 del Código Civil, posibilitan la reparación de daños no patrimoniales en las relaciones de familia y en el área convencional, respectivamente; (f) Que las doctrinas más modernas sobre el resarcimiento del daño moral, entienden que el concepto de "daño emergente" que emplea la norma del artículo 1556 del Código Civil, comprende no solo el daño pecuniario sino también el extrapatrimonial o moral; (g) Que, todavía más, se encuentra relacionado con lo resuelto la noción, con jerarquía constitucional, de igualdad ante la ley. La Corte sostiene que los bienes extrapatrimoniales de una persona, tienen un valor que de ordinario sobrepasa el de los bienes materiales y, con mayor razón es así ante el deterioro de la salud o la integridad física o psíquica; (h) Que, desde hace tiempo, se ha dado lugar a la indemnización del daño moral respecto de lo perjuicios causados por un delito o cuasidelito civil, no se divisa el motivo que justifique que se la niegue si la lesión a esos intereses extrapatrimoniales procede de la inobservancia culpable o maliciosa de uno de los contratantes a sus obligaciones; (i) Que la responsabilidad en el Derecho constituye un principio general y, referido al Derecho Civil reclama que nadie puede dañar a otro sin adquirir, correlativamente, el deber de brindarle reparación, salvo los casos en que concurre una causal de justificación o exculpación. La Corte ya había razonado en términos similares en sentencia de 14 de mayo de 2012, $\mathrm{N}^{\circ}$ de Ingreso 2.911-2011.

La raíz de esta doctrina podemos rastrearla, con seguridad, hasta el año $1954^{44}$, cuando en virtud de la controversia suscitada sobre un contrato de transporte ${ }^{45}$ nuestro más Alto Tribunal resuelve a favor de la indemnización del daño moral en sede contractual.

44 Corte Suprema, 14 de abril de 1954, No de Ingreso sin registro. "Si se admite, como ocurre en la especie, que el daño moral es indemnizable cuando proviene de un cuasidelito, es ilógico rechazarlo si se le funda en el contrato; si el hecho es uno, llámese él cuasidelito o infracción contractual; si la consecuencia es la misma: dolor, sufrimiento, desesperación a veces ante una vida tronchada, no es dable negarle su eficacia a la ley a pretexto de no haberse previsto un acto de ordinaria ocurrencia como es el accidente y sus consecuencias. Podrá, acaso, no haber a veces proporción entre la inmensidad del daño y una indemnización pecuniaria, pero como se ha dicho alguna vez "el que una cosa no pueda hacerse mejor, no es motivo para no hacerla" (Considerando $5^{\circ}$ ).

45 Aun cuando de los argumentos vertidos en la sentencia no se puede extraer conclusión alguna, no resulta ilógico pensar que dicha resolución encuentra su justificación en la circunstancia de tratarse de un contrato de seguridad, como asimismo en el hecho de la alta ocurrencia de casos referidos al mismo. Se puede agregar además que parece absurdo no conceder daño moral por el solo hecho de no existir un vínculo contractual frente al hecho lesivo que si daría origen a responsabilidad aquiliana. 
Sin lugar a dudas que en el sentido que venimos anotando resulta relevante comparar los argumentos referidos, con el contenido de la sentencia dictada por la Corte Suprema en la causa $\mathrm{N}^{\circ}$ de Ingreso $4.103-2005^{46}$, en la que se trata nuevamente nuestro tema $\mathrm{y}$, aceptando la indemnización del daño moral por infracción del contrato, pasa a sistematizar los fundamentos sobre los cuales se llega a dicha conclusión, los que podemos resumir de la siguiente manera: (a) La interpretación literal del artículo 1556 del Código Civil debida al profesor Alessandri y en virtud de la cual no procedía la indemnización del daño moral en materia contractual, ha sido abandonada por los tribunales, dado que entender que la disposición previamente citada solo se refería a perjuicios patrimoniales resulta erróneo, pues no existe tal restricción en el texto literal de la norma; (b) Existe una nueva doctrina jurisprudencial en orden a aceptar el resarcimiento del daño moral en materia contractual de la que es reflejo, entre otras, la sentencia dictada por la Corte Suprema de fecha 20 de octubre de $1994^{47}$; (c) Que el legislador acepta el daño moral, dado que la norma contenida en el artículo 1556 del Código Civil no lo excluye, como tampoco dispone que la indemnización solo comprenda o abarque el daño emergente y el lucro cesante; (d) Concepción del daño emergente que se entiende ahora integrado tanto por el daño patrimonial como por el extrapatrimonial o moral; (e) La aceptación de la doctrina, que ha ido aceptando paulatinamente la indemnización de este tipo de daño y (f) La igualdad ante la ley ${ }^{48}$, pues no se divisa razón alguna para conceder la indemnización por daño moral respecto de los perjuicios causados en virtud de un delito o cuasidelito y no hacerlo en el caso de infracción de las obligaciones contractuales ${ }^{49}$.

Evidentemente los argumentos de la sentencia dictada por la Corte Suprema con la que dimos inicio a nuestra exposición, reúnen todos los avances que en materia doctrinaria se han recogido sobre la materia, sin perjuicio de que algunos de ellos ya habían sido esgrimidos.

Por otra parte no puede dejar de citarse una interesantísima y extensa sentencia dictada por nuestro máximo Tribunal que resuelve sobre una demanda por negligencia médi$\mathrm{ca}, \mathrm{N}^{\circ}$ de Ingreso 5.849-200950, en la que conjuntamente con sentar doctrina sobre otros aspectos relevantes, como por ejemplo el contenido de la lex artis en medicina, obligación

\footnotetext{
46 Corte Suprema, 24 de septiembre de 2007, $\mathrm{N}^{\circ}$ de Ingreso 4.103-2005.

47 La misma Corte Suprema, el 5 de noviembre de 2001, reitera el criterio de reparación del daño moral, pero fundamento la decisión en los argumentos resumidos en el texto.

48 Como se puede apreciar, este es el mismo argumento que ya en 1954 la Corte Suprema esgrimía para la aceptación de la indemnización del daño moral en materia contractual. Véase supra nota 64.

49 En el mismo sentido y con los mismos argumentos: Corte Suprema, 28 de noviembre de 2006, $\mathrm{N}^{\circ}$ de Ingreso 320-2005; 11 de abril de 2007, $\mathrm{N}^{\circ}$ de Ingreso 3.291-2005; 3 de julio de 2007, $\mathrm{N}^{\circ}$ de Ingreso 3.9012005; 28 de agosto de 2007, $\mathrm{N}^{\circ}$ de Ingreso 3.750-2005; 15 de enero de 2008, $\mathrm{N}^{\circ}$ de Ingreso 3.070-2006; 7 de septiembre de 2010, $\mathrm{N}^{\circ}$ de Ingreso 1.089-2009; 11 de abril de 2011, $\mathrm{N}^{\circ}$ de Ingreso $\mathrm{N}^{\circ} 6.937-2009$; 25 de julio de 2011, $\mathrm{N}^{\circ}$ de Ingreso 3.929-2010; 20 de octubre de 2011, $\mathrm{N}^{\circ}$ de Ingreso 9.178-2010; 13 de junio de 2012, $\mathrm{N}^{\circ}$ de Ingreso 2220-2011.

50 Corte Suprema, 28 de enero de 2011, N de Ingreso 5.849-2009. En el mismo sentido y con idénticos argumentos, Corte Suprema 31 de enero de 2011, $N^{\circ}$ de Ingreso 5.818-2009, Considerando Quinto de la sentencia de reemplazo; 12 de septiembre de 2011, No de Ingreso 2.314-2010 (también referida a negligencia médica); 27 de diciembre de 2011, Nº de Ingreso 8.983-2010, voto en contra del ministro Sr. Muñoz.
} 
de medio y de resultado, termina citando al profesor FuEYo para justificar el resarcimiento del daño moral en el ámbito contractual ${ }^{51}$.

Adiciona el mismo tribunal en la causa $\mathrm{N}^{\circ}$ de Ingreso 4.931-2006 ${ }^{52}$ que la indemnización por daño moral en materia contractual “...procede únicamente en eventos en los que la convención extiende su ámbito al resguardo o protección de bienes extrapatrimoniales o cuando comprende intereses que claramente ya no conciernen al patrimonio sino a la personalidad moral del sujeto, como su afectividad, su estabilidad emocional, su integridad, su moral, etc." (Considerando Décimo).

Hasta aquí podemos decir que hoy ya no se discute la factibilidad de la indemnización por daño moral derivado del incumplimiento de un contrato y que el camino iniciado tímidamente en 1954 y corroborado en el año 1994, fructifica en una jurisprudencia uniforme de la Primera Sala de la Corte Suprema que, de forma reiterada, ha resuelto de la manera antes dicha.

Pese a lo anterior, se extraña una discusión en torno a un tema íntimamente conectado, pero distinto y que se resume en el cuestionamiento en torno a si todo daño moral, solo por el hecho de serlo, es indemnizable o si se requiere del cumplimiento de ciertos requisitos para que sea susceptible de reparación. En este sentido cobra relevancia el incipiente pronunciamiento del máximo Tribunal emitido en fallo que data de 1 de octubre de $2012^{53}$, en el cual se escudriña sobre tal dilema aparentando ser el antecedente del cuestionamiento que debe provenir en las decisiones futuras, desde que se refiere a la previsibilidad del daño ocasionado frente al incumplimiento de un contrato de arrendamiento, señalando la decisión de mayoría: “...para la contraparte de quien contrata la custodia del vehiculo es plenamente previsible suponer que el deterioro o robo en este, que configura el incumplimiento de obligación, va a causar la molestia o aflicción que antes se mencionaba". (Considerando Undécimo) Luego agrega el fallo, en la reflexión siguiente y refiriéndose a los daños extrapatrimoniales: “...que procede su indemnización toda vez que el incumplimiento era imputable a culpa de dicha concesionaria, que el deudor se encuentra en mora, que la ocurrencia de los mismos era previsible al tiempo de contratar y que surgen como consecuencia inmediata y directa de tal infracción, lo que permite atribuirle las calidades de daños previstos y directos, respectivamente".

Por su parte, el voto minoritario ${ }^{54}$ se ocupa de desarrollar latamente la problemática a la que nos enfrentamos y esgrime al efecto: "Que no se discute ya en doctrina que es posible que el incumplimiento contractual pueda dar lugar a una indemnización por daño moral, si bien la respuesta acerca de la procedencia de la misma no puede formularse en términos absolutos, pues la naturaleza y el tipo especifico de contrato serán relevantes a la hora de determinar

\footnotetext{
51 En el mismo sentido, aunque con una redacción algo distinta en el fundamento: Corte Suprema, 23 de junio de 2011, $\mathrm{N}^{\circ}$ de Ingreso 7.234-2009.

52 Corte Suprema, 25 de marzo de 2008, $\mathrm{N}^{\circ}$ de Ingreso 4.931-2006; 25 de septiembre de 2008, $\mathrm{N}^{\circ}$ de Ingreso 59-2007; 29 de octubre de 2008, $\mathrm{N}^{\circ}$ de Ingreso 4.727-2007; 7 de enero de 2009, $\mathrm{N}^{\circ}$ de Ingreso 5.814-2007; 26 de enero de 2009, $\mathrm{N}^{\circ}$ de Ingreso 5.329-2007; 7 de septiembre de 2009, $\mathrm{N}^{\circ}$ de Ingreso 1.870-2008; 5 de octubre de 2009, $\mathrm{N}^{\circ}$ de Ingreso 1.922-2008; 26 de octubre de 2009, $\mathrm{N}^{\circ}$ de Ingreso 1.772-2008.

53 Corte Suprema, $N^{\circ}$ de Ingreso 4.415-2010.

54 Pronunciado por la ministra Sra. Maggi y el abogado integrante Sr. Prado.
} 
si el menoscabo moral que se pretende derivado del incumplimiento de una obligación determinada resultaba o no previsible para los contratantes, es decir, si el acreedor de la indemnización que se demanda tomó a su cargo el riesgo de lesionar intereses extrapatrimoniales de su contraparte". (Considerando Segundo). Añaden los disidentes: "En este contexto, la previsibilidad del daño podrá provenir de la propia naturaleza de la obligación contraida, si ella está directamente vinculada con intereses extrapecuniarios, o de las circunstancias que rodean la celebración del contrato, si estas conducen natural y razonablemente a suponer que el incumplimiento contractual acarreará consecuencias de orden extrapatrimonial' (Considerando Cuarto). Para razonar como corolario en el fundamento Séptimo que: “...el contratante incumplidor debe indemnizar el daño moral cuando ha estado en situación de preverlo al tiempo del contrato, atendiendo a criterios objetivos, sea en razón del contenido de la convención, de la naturaleza de las obligaciones contraidas conforme a la buena fe, o en atención a los riesgos que normalmente pueden derivar del incumplimiento" 55.

Precisamente es en vinculación con este último derrotero, esbozado precedentemente $y$, particularmente, en torno a la verificación de determinados presupuestos para que sea indemnizable el daño moral, que se encuentra centrada actualmente la discusión que está presente en la doctrina y jurisprudencia española y, es a esta última a la que dedicaremos el siguiente apartado.

\section{ANÁLISIS DE LA JURISPRUDENCIA DEL TRIBUNAL SUPREMO ESPAÑOL}

Actualmente en la jurisprudencia ${ }^{56}$ del Tribunal Supremo español${ }^{57}$, se ha superado -tal como en Chile- la discusión en torno a la procedencia de la reparación del daño moral por incumplimiento de contrato ${ }^{58}$, generándose a partir de ahí un giro interpretativo que resultó en una concepción cada vez más amplia del concepto de daño moral, que ya no solo incluye el «sufrimiento psíquico», sino también «el impacto o sufrimiento psíquico o espiritual, sensación anímica de inquietud, pesadumbre, temor o presagio o incertidumbre» 59 . Tomando como base estos antecedentes, poco tendría que apuntarse en torno a si dicho Tribunal acepta o no la reparación del daño moral por infracción contractual, pero donde cobra rele-

55 El voto disidente finalmente concluye que en la situación particular que analiza no concurren los criterios aludidos, argumentando que tratándose "...de un contrato de carácter preponderantemente económico, como es el arrendamiento de un estacionamiento, en que la inobservancia de la obligación de custodia de un automóvil asumida por el arrendador, si bien lo obliga a resarcir todos los perjuicios materiales que de su falta de diligencia hayan derivado, no lo fuerza a responder de situaciones ajenas al contenido del contrato y que no pudo razonablemente prever, como el cuantioso menoscabo moral que al actor reclama a causa de "molestias laborales y de tiempo invertidas en la solución del problema", circunstancias que, al margen de toda otra consideración, tampoco responden al concepto de daño moral elaborado por la doctrina y la jurisprudencia”.

56 Las sentencias citadas han sido seleccionadas de la base de jurisprudencia que se encuentra en el sitio web oficial del Poder Judicial español (www.poderjudicial.es), especialmente de la Sala Civil del Tribunal Supremo de ese país. No se trata de una búsqueda exhaustiva que pretenda un análisis acabado del tema, cuestión que excede las limitaciones de este trabajo, sino que a título ejemplar para permitir marcar cierta línea en el desarrollo de la doctrina de dicho Tribunal.

57 Tribunal Supremo, 9 de mayo de 1984, RJ 2403/1984; 13 de diciembre de 1984, RJ 6111/1984.

58 En este sentido, Tribunal Supremo, 3 de mayo de 2006, RJ 4070/2006.

59 Tribunal Supremo, 31 de mayo de 2000, RJ 5089/2000. 
vancia el análisis es en la tendencia que se da en la jurisprudencia española a la imposición de limitaciones a su reparación ${ }^{60}$.

Así esbozado el problema, resulta conveniente remitirse a un fallo reciente, del 13 de abril de $2012^{61}$, en el que, para lo que interesa a nuestro estudio, el tribunal de primera instancia condenó al pago de indemnización por daño moral, fundando dicha decisión en las situaciones anímicas de sufrimiento, incertidumbre, desazón y frustración que debieron soportar los demandantes como consecuencia de las infracciones al contrato denunciadas ${ }^{62}$. A su vez, el Tribunal Supremo, al resolver, recoge su propia doctrina jurisprudencial de los últimos años en relación al daño moral y la infracción a los artículos 1101 y 1106 del Código Civil ${ }^{63}$ y continúa discurriendo en torno a las dificultades de prueba que representa la acreditación del perjuicio moral y la avaluación económica de los daños inmateriales y que pueden variar en función de la sensibilidad de la persona, concluyendo que la doctrina y la jurisprudencia admiten su existencia, si bien con cautela para evitar «reclamaciones injustifcadas» o amparadas en «incumplimiento de escasa entidad».

Precisamente en este punto, como adelantábamos anteriormente, es donde más se advierten diferencias con el camino seguido por la jurisprudencia de la Corte Suprema chilena, pues esta última, como hemos tenido oportunidad de apreciar ${ }^{64}$, más bien discurre sobre si hubo o no daño moral -de manera que si existe, se indemniza sin posterior análisis- que con las exigencias para que este, una vez acreditado sea finalmente objeto de reparación.

Otro interesante punto viene dado por el acápite en el que se refiere a la configuración del daño moral, su determinación y las finalidades de su resarcimiento, dado que sostiene que el pago de su importe indemniza a los perjudicados, ex nunc (desde ahora), pero no ex tunc (desde entonces), por lo que la reparación solo puede ser hacia el futuro.

Absolutamente concordante con lo recién expuesto, resulta ser la sentencia dictada con fecha 15 de julio de $2011^{65}$ en la que el Tribunal Supremo analizó la existencia del daño moral, declarando la ocurrencia de los mismos y su entidad, la inseparabilidad del vicio de ruina o daño material con la zozobra e intranquilidad que generó.

Como se puede apreciar si bien la jurisprudencia del Tribunal Supremo ha reconocido que el daño moral es resarcible en la responsabilidad contractual, al mismo tiempo sostiene que no siempre debe ser indemnizado por el que lo causa. La obligación de reparación, entonces, no tiene un alcance universal, sino que este debe ser delimitado en función

60 Rodríguez Guitián (2008) pp. 142-163.

61 Sentencia del Tribunal Supremo, 13 de abril de 2012, RJ 3065/2012. En el mismo sentido, aunque con argumentos ligeramente diferentes, Tribunal Supremo, 12 de abril de 2012, RJ 2545/2012; 27 de febrero de 2012, RJ 209/2012.

62 Considerando Primero de la sentencia citada.

63 "... el daño moral se identifica con las consecuencias no patrimoniales representadas por el impacto o sufrimiento psíquico o espiritual que en algunas personas pueden producir ciertas conductas, actividades e incluso resultados... y se indemniza junto al daño patrimonial, bien mediante la aplicación de reglas especificas, como la del artículo 1591 del Código Civil, bien mediante las generales de responsabilidad contractual o extracontractual de los artículos 1101 y 1902 del mismo texto legal" (Considerando Cuarto).

64 Véase supra, pp. 12 ss.

65 RJ 4900/2011. 
del contenido del contrato y de los criterios normativos de imputación objetiva que resultan del ordenamiento jurídico ${ }^{66}$.

Tratándose de la responsabilidad derivada del incumplimiento de un contrato tiene suficiente relevancia, por lo general, para entender excluida la obligación de responder por daños morales el hecho de que en un contrato de contenido predominantemente económico no se halle prevista y no se infiera de su contenido y consecuencias conforme a la buena fe, al uso y a la ley una obligación especial de diligencia para cubrir todos o algunos de los posibles daños morales derivados del incumplimiento ${ }^{67}$. Se inserta así un nuevo elemento que sirve para frenar el indiscriminado resarcimiento del daño moral contractual: la previsibilidad. Y precisamente es por dicho factor y el antes mencionado de la "entidad del daño", que en el caso en comento rechaza la demanda, pues se sostiene que la existencia de un vicio en la construcción no lleva aparejada de forma inseparable la situación de «zozobra e intranquilidad», ni supone tampoco la frustración del deseo de obtener una vivienda en circunstancias óptimas para ser habitada.

En septiembre de $2011^{68}$, el Tribunal Supremo se pronuncia respecto de la acción intentada contra un abogado por incumplimiento de sus obligaciones contractuales y en ella plantea un criterio un tanto distinto del enunciado previamente, pues resuelve que efectivamente hay responsabilidad contractual ${ }^{69}$ y que cuando el daño por la que se exige consiste en la frustración de una acción judicial, el daño deba calificarse como patrimonial ${ }^{70}$. Desde esta perspectiva, sostiene, que mientras todo "...daño moral efectivo, siempre que deba imputarse jurídicamente a su causante, debe ser objeto de compensación, aunque sea en una cuantía mínima...", la valoración de la pérdida de oportunidades de carácter pecuniario abre un abanico que abarca desde la fijación de una indemnización equivalente al importe económico del bien o derecho reclamado, hasta la negación de toda indemnización.

En una sentencia de 9 de diciembre de $2010^{71}$, el Tribunal Supremo acoge la demanda por daños morales padecidos por las demandantes, calificando en diversos grados el daño moral para verificar el monto de la reparación: así califica el daño moral como «relevante en grado moderado", "más intenso", "en grado más elevado».

Un poco posterior, con fecha 23 de diciembre de $2010^{72}$, el Tribunal Supremo niega la indemnización por daño moral en un caso en que se discute la infracción de un contrato de asesoría para la presentación de reclamaciones por facturación de servicios de energía eléctrica, señalando que dicha reparación no procede pues no se justificó ninguna lesión no material de entidad por parte de la actora ${ }^{73}$.

66 Tribunal Supremo, 10 de marzo de 2009, RJ 1882/2009; 12 de abril de 2012, RJ 224/2012.

67 Véase supra, nota 78.

68 RJ. 7744/2011.

69 Tribunal Supremo, 21 de junio de 2007, RJ 4480/2007.

70 Tribunal Supremo, 28 de febrero de 2008, RJ 110/2008, 3 de julio de 2008 RJ 4421/2008, 12 de mayo de 2009, RJ 2680/2009.

71 Tribunal Supremo, 9 de diciembre de 2010, RJ 545/2010.

72 Tribunal Supremo, 23 de diciembre de 2010, RJ 6953/2010.

73 Considerando Sexto. 
Como se puede apreciar, la discusión de la jurisprudencia española se centra hoy en fijar limitaciones a la indemnización del daño moral contractual, toda vez que a quien le resulte imputable el mismo no siempre ha de repararlo, sino que solo estará frente a esta obligación en la medida que dicho daño haya sido previsible y de una entidad importante.

\section{CONCLUSIONES}

1. Pese a no existir norma expresa y tal como ya han señalado diversos autores, la incertidumbre relativa a la procedencia del daño moral derivado del incumplimiento o cumplimiento defectuoso o tardío del contrato, ha quedado zanjada positivamente por la jurisprudencia de la Sala Civil de la Corte Suprema chilena. Sobre el particular y también a falta de texto legal, los dictámenes emitidos por el Tribunal Superior español dan cuenta de una solución similar, recurriendo para ello a un concepto amplio de daño moral que incluye la lesión de cualquier interés jurídico -sea o no patrimonial-aun cuando a ella han arribado con anterioridad demostrando que el sistema nacional le sigue de reata.

2. En la realidad española se ha discutido profusamente en torno a la patrimonialidad de la prestación y su relación con la extrapatrimonialidad del daño moral, primer obstáculo teórico para proceder a su indemnización, cuestión, que salvo excepciones muy destacadas, no ha movido mayores controversias en nuestro país, ni a nivel doctrinario, ni a nivel jurisprudencial.

3. No obstante el avance constatado en nuestro sistema, aun se reclama a la jurisprudencia nacional -como se ha advertido por la doctrina- pronunciamiento en relación con la previsibilidad de los daños, como elemento que determina la pertinencia de la reparación del daño moral derivado del contrato, a la luz de lo que prevé el art 1558 del Código Civil, toda vez que los sentenciadores se han limitado a manifestar su parecer en términos generales sobre la procedencia de esta categoría de daños, empero han omitido analizar la gravedad de los mismos y observar si son de aquellos que entran en la categoría de previstos o previsibles a la data de la celebración del contrato, a fin de dar sentido a la norma y con ello evitar los excesos que pudieran verificarse en el entendido que no todos los perjuicios de la naturaleza antes dicha corresponde sean resarcidos.

Por el contrario, la jurisprudencia española se ha preocupado de fijar límites a la reparación del daño moral en materia contractual: (a) respecto de la entidad del daño, se exige que este vaya más allá de las meras molestias o frustraciones derivadas del incumplimiento contractual, pues el riesgo del mismo se entiende implícito en toda relación contractual; (b) en cuanto al tenor del artículo 1107 del Código Civil español, se hace una doble exigencia, pues además de que el daño moral sea objetivamente imputable al deudor, se solicita que sea previsible al momento de constituirse la obligación.

4. Aun más se extraña la discusión en torno a la previsibilidad del daño en nuestro país, si se considera que el artículo 1107 del Código Civil español es el equivalente a nuestro artículo 1558 .

5. Los argumentos para acoger la indemnización del daño moral por incumplimiento contractual han sido variados, pero es interesante destacar que, incluso, la garantía de los derechos extrapatrimoniales tiene rango constitucional que, en nuestro caso, se funda en el 
artículo $19 \mathrm{~N}^{\circ} 1$ y 4 de la Carta Fundamental, todo ello recogido por el principio de reparación integral del sujeto, que también ha ido encontrando el debido reconocimiento.

6. La validez que la jurisprudencia le ha dado a la indemnización del daño moral en materia contractual, ha llevado a que los tribunales y particularmente nuestra Corte Suprema, hayan analizado sistemáticamente el ordenamiento jurídico, abandonando la idea de un análisis exegético y fragmentario de las normas. Es así como se puede apreciar que, tanto en la jurisprudencia chilena como en la española se ha argumentado en torno a que no existen razones de justicia para desestimar el resarcimiento del daño moral en sede contractual, cuando ha sido unánimemente aceptado en el ámbito extracontractual.

7. La evolución de nuestra jurisprudencia debería avanzar en tres sentidos, tal como ya lo ha hecho la española: (a) dar un nuevo concepto de daño moral, más amplio que aquel que tradicionalmente se ha aceptado y en el que deben incluirse no solo los derechos subjetivos sino también los intereses extrapatrimoniales; (b) la indemnización del daño moral por incumplimiento contractual es excepcional y para que proceda, se requiere cumplir con una serie de exigencias, dentro de las cuales la previsibilidad y la entidad del daño son fundamentales, y (c) el daño moral, como todo perjuicio, debe acreditarse para que sea reparado.

\section{JURISPRUDENCIA CITADA}

\section{Corte Suprema de Chile}

Compañia Chilena de Electricidad Ltda. con Morales (1954): Corte Suprema, 14 de abril de 1954 (acción de indemnización de perjuicios), Repertorio, tomo 51, sección 1a, pp. 74-76.

Mouthon con Banco de Chile (1994): Corte Suprema, 20 de octubre de 1994 (acción de indemnización de perjuicios), Revista de Derecho y Jurisprudencia, tomo 91 sección 1a, pp. 101-105.

Ocaranza con Robinson (2006): Corte Suprema, 28 de noviembre de 2006 (acción de indemnización de perjuicios), $\mathrm{N}^{\circ}$ de Ingreso 320-2005.

Pizarro con Isapre Banmédica S. A. (2007): Corte Suprema, 13 de marzo de 2007 (acción de cumplimiento de contrato e indemnización de perjuicios), No de Ingreso 7.118-2007.

Aros con Zoffoli (2007): Corte Suprema, 11 de abril de 2007 (acción de indemnización de perjuicios) $\mathrm{N}^{\circ}$ de Ingreso 3.291-2005.

Hermosilla con Promotora CMR Falabella S. A. (2007): Corte Suprema, 3 de julio de 2007 (acción de nulidad absoluta), $\mathrm{N}^{\circ}$ de Ingreso 3.901-2005.

Le Dantec con Banco de Chile (2007): Corte Suprema, 28 de agosto de 2007 (acción de indemnización de perjuicios) $\mathrm{N}^{\circ}$ de Ingreso 3.750-2005.

Montecinos con Hospital Clínico Pontificia Universidad Católica de Chile (2007): Corte Suprema, 24 de septiembre de 2007 (acción de indemnización de perjuicios) No de Ingreso $4.103-2005$.

Ojeda con Editorial Jurídica ConoSur Ltda. (2008): Corte Suprema, 15 de enero de 2008 (acción de cobro de pesos) $N^{\circ}$ de Ingreso 3.070-2006. 
Rochet con Oksenberg (2008): Corte Suprema, 25 de marzo de 2008 (acción de indemnización de perjuicios) $\mathrm{N}^{\circ}$ de Ingreso 4.931-2006.

Lazcani con Inmobiliaria Fourcade S. A. (2008): Corte Suprema, 29 de octubre de 2008 (acción de indemnización de perjuicios) $\mathrm{N}^{\circ}$ de Ingreso 4.727-2007.

Alarcón con Empresa Constructora Emasil S. A. (2008): Corte Suprema, 25 de septiembre de 2008 (acción de indemnización de perjuicios) N $N^{\circ}$ de Ingreso 59-2007.

Orozco con Banco de Chile (2009): Corte Suprema, 7 de enero de 2009 (acción de indemnización de perjuicios) $\mathrm{N}^{\circ}$ de Ingreso 5.814-2007.

Zepeda con Empresa de Obras y Montajes Ovalle Moore S. A. (2009): Corte Suprema, 26 de enero de 2009 (acción de indemnización de perjuicios) $\mathrm{N}^{\circ}$ de Ingreso 5.329-2007.

Herrera con Banco Santander S. A. (2009): Corte Suprema, 7 de septiembre de 2009 (acción de indemnización de perjuicios) $\mathrm{N}^{\circ}$ de Ingreso 1.870-2008.

Olguin con Sociedad de Inversiones Automotrices S. A. (2009): Corte Suprema, 5 de octubre de 2009 (acción de indemnización de perjuicios) Nº de Ingreso 1.922-2008.

Mesina con Reveco (2009): Corte Suprema, 26 de octubre de 2009 (acción de nulidad absoluta de contrato) $\mathrm{N}^{\circ}$ de Ingreso 1.772-2008.

Fernández con E. Kovakcs S. A. (2010): Corte Suprema, 25 de mayo de 2010 (acción redhibitoria) $\mathrm{N}^{\circ}$ de Ingreso 5.849-2008.

Netz con The Wessex School (2010): Corte Suprema, 7 de septiembre de 2010 (acción de indemnización de perjuicios) $N^{\circ}$ de Ingreso 1089-2009.

Morin con Empresa Chilquinta Energía S. A. (2010): Corte Suprema, 19 de octubre de 2010 (acción de indemnización de perjuicios) Nº de Ingreso 7.076-2010.

Alarcón con Inversiones e Inmobiliaria Campanario Limitada (2011): Corte Suprema, 31 de enero de 2011 (acción de indemnización de perjuicios) Nº de Ingreso 5.818-2009.

Suazo con Corporación Nacional del Cobre (2011): Corte Suprema, 4 de abril de 2011(acción de indemnización de perjuicios) $\mathrm{N}^{\circ}$ de Ingreso 7.270-2009.

Vicente con Banco Citibank N. A. (2011): Corte Suprema, 11 de abril de 2011(acción de indemnización de perjuicios) $\mathrm{N}^{\circ}$ de Ingreso $\mathrm{N}^{\circ}$ 6.937-2009.

Kreuzer Pacheco Hermanos con Ronald Chaytor y Cía. Ltda. (2011): Corte Suprema, 23 de junio de 2011 (acción de resolución de contrato con indemnización de perjuicios) $\mathrm{N}^{\circ}$ de Ingreso 7.234-2009.

Mora con Isapre Colmena Golden Cross (2011): Corte Suprema, 25 de julio de 2011 (acción de indemnización de perjuicios) $\mathrm{N}^{\circ}$ de Ingreso 3.929-2010.

Cortes con García (2011): Corte Suprema, 12 de septiembre de 2011(acción de indemnización de perjuicios) $\mathrm{N}^{\circ}$ de Ingreso 2.314-2010.

De la Torre con Chomali (2011): Corte Suprema, 20 de octubre de 2011(acción de resolución de contrato con indemnización de perjuicios) $\mathrm{N}^{\circ}$ de Ingreso 9.178-2010.

Viveros con Correa (2011): Corte Suprema, 27 de diciembre de 2011 (acción de indemnización de perjuicios) $\mathrm{N}^{\circ}$ de Ingreso 8.983-2010.

Olivi con Banco Santander Chile (2012): Corte Suprema, 30 de marzo de 2012 (acción de terminación de contrato con indemnización de perjuicios) $\mathrm{N}^{\circ}$ de Ingreso 2.560-2011.

Ramírez con Ruta de Los Ríos Sociedad Concesionaria S. A. (2012): Corte Suprema, 14 de mayo de 2012 (acción de indemnización de perjuicios) Nº de Ingreso 2.911-2011. 
Canet con Colegio Salesianos de Valparaíso (2012): Corte Suprema, 11 de junio de 2012 (acción de indemnización de perjuicios) $\mathrm{N}^{\circ}$ de Ingreso 7.974-2009.

Toro con Concha (2012): Corte Suprema, 13 de junio de 2012 (acción de indemnización de perjuicios) $\mathrm{N}^{\circ}$ de Ingreso 2220-2011.

Bazan con Sociedad Comercial Concesionaria Subterra S. A. (2012): Corte Suprema, 1 de octubre de 2012 (acción de indemnización de perjuicios) Nº de Ingreso 4415-2010.

\section{Tribunal Supremo Español (Sala Civil)}

Miguel Ángel con Luis (1984): Tribunal Supremo, 9 de mayo de 1984 (acción de incumplimiento de contrato) RJ 2403/1984.

Antonio con Galletas Fontaneda (1984): Tribunal Supremo, 13 de diciembre de 1984 (acción de indemnización de perjuicios) RJ 6111/1984.

Manantiales S. A. con Pedro (2000): Tribunal Supremo, 31 de mayo de 2000 (acción de indemnización de perjuicios) RJ 5089/2000.

Caja de Ahorro con María (2006): Tribunal Supremo, 3 de mayo de 2006 (acción de incumplimiento de contrato) RJ 4070/2006.

Esteban con AIG Eurepe (2007): Tribunal Supremo, 21 de junio de 2007 (acción de indemnización de perjuicios) RJ 4480/2007.

Marina con Alzira (2008): Tribunal Supremo, 28 de febrero de 2008 (acción de incumplimiento de contrato) RJ 110/2008.

Juan Pablo con Zurich (2008): Tribunal Supremo, 3 de julio de 2008 (acción de incumplimiento de contrato) RJ 4421/2008.

Gervasio con Inpevar (2009): Tribunal Supremo, 10 de marzo de 2009 (acción de incumplimiento de contrato) RJ 1882/2009.

Renfe con Iván (2009): Tribunal Supremo, 12 de mayo de 2009 (acción de incumplimiento de contrato) RJ 2680/2009.

Humberto con Ocaso S. A. (2010): Tribunal Supremo, 9 de diciembre de 2010 (acción de indemnización de perjuicios) RJ 545/2010.

Damm S.A. con Ibérica Control y Proyectos (2010): Tribunal Supremo, 23 de diciembre de 2010 (acción de incumplimiento de contrato) RJ 6953/2010.

Porfirio con Tecsa S. A. (2011): Tribunal Supremo, 15 de julio de 2011 (acción de incumplimiento de contrato) RJ 4900/2011.

Luis Pedro con Abilio (2011): Tribunal Supremo, 9 de agosto de 2011(acción de incumplimiento de contrato) RJ. 7744/2011.

Daniel con Lufthansa Lineas Aéreas Alemanas (2012): Tribunal Supremo, 27 de febrero de 2012 (acción de indemnización de perjuicios) RJ 209/2012.

Herminio con Encoval S. L. (2012): Tribunal Supremo, 12 de abril de 2012 (acción de indemnización de perjuicios) RJ 2545/2012

Comunidad de Propietarios Avenida (2012): Tribunal Supremo, 13 de abril de 2012(acción de incumplimiento de contrato) RJ 3065/2012. 


\section{BIBLIOGRAFÍA CITADA}

Abeliuk Manasevich, René (I993): Las obligaciones (Santiago, Editorial Jurídica de Chile) pp. 1066.

Abeliuk Manasevich, René (2003): Las obligaciones (Santiago, Editorial Jurídica de Chile, cuarta edición actualizada y aumentada) pp. 763.

Aedo Barrena, Cristian (2001): El daño moral en la responsabilidad contractual y extracontractual (Valparaíso, Editorial Libromar Ltda.) pp. 517.

Alessandri Rodríguez, Arturo (1943): De la responsabilidad extracontractual en el derecho civil chileno (Santiago, Ediar) pp. 716.

Álvarez Vigaray, Rafael (1966): "La responsabilidad por daño moral”, Anuario de Derecho Civil, pp. 81 ss.

Baltierra Retamal, Enrique (1956): Indemnización de daño moral en la legislación civil chilena (Memoria de Prueba, Universidad de Chile) pp 72.

Barrientos Zamorano, Marcelo (2010): "Análisis preliminar de la jurisprudencia de la Corte Suprema sobre daños en causas por incumplimientos contractuales civiles de los años 2002 a 2007”, Revista Chilena de Derecho, vol. 37 N 1, pp. 163-170.

Barrientos Zamorano, Marcelo (2007): El resarcimiento por daño moral en España y Europa (Salamanca, Ratio Legis) pp. 574.

Barrientos Zamorano, Marcelo (2007): "Los daños extrapatrimoniales que se previeron o pudieron preverse al tiempo del contrato", Revista Chilena de Derecho, vol. 34, $\mathrm{N}^{\circ} 1$, pp. 7-22.

Barrientos Zamorano, Marcelo (2008): "Del daño moral al daño extrapatrimonial: la superación del pretium doloris”, Revista Chilena de Derecho, vol. 35, № 1, pp. 85-106.

Barros Errázuriz, Alfredo (1932): Curso de Derecho Civil, vol. II (Santiago, Editorial Nascimento) pp. 382.

Butrón Firpo, Roberto (1920): "La indemnización del daño moral en nuestra legislación", Revista de Derecho, Jurisprudencia y Ciencias Sociales, dic. pp. 139-161.

Cárdenas Villarreal, Hugo (2006): "Daño moral por incumplimiento de contrato: un réquiem para la uniformidad jurisprudencial”, Revista Chilena de Derecho, vol. 33, №3, pp. 585-593.

Castán Tobeñas, José (1993): Derecho civil español común y foral (Madrid, Reus) pp. 1224.

Carrasco Perera, Ángel (1989): "Comentario a los arts. 1101, 1106 y 1107 del Código Civil español”, Comentarios al Código Civil y Compilaciones Forales, tomo XV, vol. I, pp. 324.

Corral Talciani, Hernán (2003): Lecciones de responsabilidad extracontractual (Santiago, Editorial Jurídica de Chile) pp. 399.

Corral Talciani, Hernán (2010): Contratos y daños por incumplimiento (Santiago, Abedelo Perrot) pp. 328.

Corral Talciani, Hernán (2010): "Concurrencia de acciones de responsabilidad civil contractual y extracontractual en los daños causados por accidentes del trabajo", Revista Chilena de Derecho Privado, N 14 , pp. 69-107.

Court Murasso, Eduardo (1998): "Responsabilidad civil médica", Revista de Derecho de la Universidad Católica de Valparaíso, vol. XIX, pp. 277-293. 
Cristóbal Montes, Ángel (1990): “El daño moral contractual”, Revista de Derecho Privado, pp. 2-12.

De Diego, Felipe (1959): Instituciones de Derecho Civil (Madrid [s/n]) pp. 476.

De la Maza, Lorenzo (1988): "La responsabilidad civil que puede derivar de la actividad médica”, Revista Chilena de Derecho, vol. 15, N 1, pp. 29 y ss.

Díez-Picazo, Luis (1999): Derecho de daños (Madrid, Civitas) pp. 367.

Díez-Picazo, Luis (2008): El escándalo del daño moral (Pamplona, Editorial Aranzandi S. A.) pp. 102.

Díez Schwerter, José Luis (1997): El daño extracontractual. Jurisprudencia y doctrina (Santiago, Editorial Jurídica de Chile) pp. 291.

Domínguez Águila, Ramón (1990): "Consideraciones en torno al daño en la responsabilidad civil. Una visión comparatista”, Revista de Derecho de la Universidad de Concepción $\mathrm{N}^{\circ}$ 188, año LVIII, jul-dic, pp. 125-168.

Domínguez Águila, Ramón (2000): "Responsabilidad contractual. Ausencia de daño moral, Revista de Derecho de la Universidad de Concepción N²07, año LXVIII, ene.-jun., pp. 173-177.

Domínguez Águila, Ramón (2001): "Daño moral contractual. Examen de laboratorio por VIH. Ausencia de norma que impida esa reparación en materia contractual”, Revista de Derecho de la Universidad de Concepción N²09, año LXIX, pp. 233-238.

Domínguez Águila, Ramón (2005): "Instituciones jurisprudenciales en el Código Civil chileno", Sesquicentenario del Código Civil de Andrés Bello. Pasado, presente y futuro de la codificación (Santiago, LexisNexis) pp. 331-357.

Domínguez Águila, Ramón (2010): “Los límites al principio de la reparación integral”, Revista Chilena de Derecho Privado, N 15, pp. 9-28.

Domínguez Águila, Ramón y Domínguez Benavente, Ramón (1993): “Responsabilidad contractual. Daño moral. Cúmulo de responsabilidades. Prueba del daño moral”, Revista de Derecho de la Universidad de Concepción N 193, año LXI, pp. 159-163.

Domínguez Águila, Ramón y Domínguez Benavente, Ramón (1994): "Daño moral en la responsabilidad contractual ausencia de norma excluyente de su reparación", Revista de Derecho de la Universidad de Concepción N 196, año LXII, pp. 155-160.

Domínguez Hidalgo, Carmen (1998): "La indemnización por daño moral. Modernas tendencias en el Derecho Civil chileno y comparado", Revista Chilena de Derecho, vol. $25 \mathrm{~N}^{\circ} 1$, pp. 27-55.

Domínguez Hidalgo, Carmen (1999): "Aspectos modernos de la reparación por daño moral: contraste entre el derecho chileno y el derecho comparado", Revista de Derecho de la Universidad Católica del Norte, año 6, pp. 29-46.

Domínguez Hidalgo, Carmen (2000): El daño moral (Santiago, Editorial Jurídica de Chile) pp. 782.

Domínguez Hidalgo, Carmen (2006): "El daño moral en Chile. Contornos y problemas”, Revista Anales de Derecho UC. Tema de responsabilidad civil N 1, pp. 307-328.

Domínguez Hidalgo, Carmen (2006): "La reparación del daño moral derivado del contrato en el derecho civil chileno: realidad y límites", Cuaderno de Análisis Jurídico III, pp. 227-244. 
Domínguez Hidalgo, Carmen (2011): "El principio de reparación integral del daño y su contenido: algunas consecuencias para el Derecho Chileno", Estudios de Derecho Civil, Obligaciones, en Hernán Corral Talciani, Alejandro Guzmán Brito, Carlos Pizarro Wilson, María Sara Rodríguez Pinto, Susan Turner Saelzer, Juan Andrés Varas Braun (coord.), (Santiago, Abedelo Perrot) pp. 659-673.

Fueyo Laneri, Fernando (1965): "Sobre el daño extrapatrimonial en el cumplimiento del contrato", Revista Jurídica de Buenos Aires, pp. 67-110.

Fueyo Laneri, Fernando (1972): "De nuevo sobre el daño extrapatrimonial y su resarcibilidad”, Colección Justitia et Jus, Sección de Investigaciones, No 8, 1972.

Fueyo LANeri, Fernando (1990): Instituciones de derecho civil moderno (Santiago, Editorial Jurídica de Chile) pp. 602.

Fueyo Laneri, Fernando (2004): Cumplimiento e incumplimiento de las obligaciones (Santiago, Editorial Jurídica de Chile, tercera edición actualizada) pp. 650.

Gandarillas Serani, Cristián (2011): "Algunas consideraciones acerca del deber de mitigación o minimización del daño frente al incumplimiento contractual”, Estudios de Derecho Civil, Obligaciones, tomo II, en Hernán Corral Talciani, Alejandro Guzmán Brito, Carlos Pizarro Wilson, María Sara Rodríguez Pinto, Susan Turner Saelzer, Juan Andrés Varas Braun (coord.), (Santiago, Abedelo Perrot) pp. 519-537.

Gatica Pacheco, Sergio (1956): Aspectos de la indemnización de perjuicios por incumplimiento de contrato, Memoria de Prueba, Universidad de Chile. pp. 58.

Hernández Gil, Antonio (1960): "El problema de la patrimonialidad de la prestación”, Revista de Derecho Privado, pp. 273 y ss.

Illanes Ríos, Claudio (1994): "El daño moral en la responsabilidad contractual”, Separata del Colegio de Abogados de Chile.

Jana, Andrés y Tapıa, Mauricio (2004): "Daño moral en la responsabilidad contractual a propósito de un fallo de la Corte Suprema de 5 de noviembre de 2001", Cuadernos de Análisis Jurídico, $\mathrm{N}^{\circ}$ 1, pp. 171-209.

León Hurtado, Avelino (1983): El objeto en los actos jurídicos (Santiago, Editorial Jurídica de Chile, segunda edición actualizada) pp. 151.

Mayo, Jorge y Prevot, Juan (2007): Responsabilidad contractual (Buenos Aires, Editorial La Ley) pp. 535.

Miquel, Juan Luis (2008): Resolución de los contratos por incumplimiento (Buenos Aires, LexisNexis, tercera edición actualizada) pp. 305.

Molinari Valdés, Aldo (2004): De la responsabilidad civil al derecho de daños y tutela preventiva civil (Santiago, LexisNexis) pp. 247.

Parellada, Carlos (2006): "La evolución del pensamiento sobre el daño en la República Argentina”, Revista Anales de Derecho UC. Tema de responsabilidad civil N 1, pp. 149-164.

Pizarro Wilson, Carlos (2011): "Hacia un sistema de remedios al incumplimiento contractual”, Estudios de Derecho Civil, Obligaciones, Tomo II, en Hernán Corral Talciani, Alejandro Guzmán Brito, Carlos Pizarro Wilson, María Sara Rodríguez Pinto, Susan Turner Saelzer, Juan Andrés Varas Braun (coord.), (Santiago, Abedelo Perrot) pp. 303-310. 
Pizarro Wilson, Carlos, "La responsabilidad contractual en derecho chileno", Disponible en: <www.fundaciónfueyo.udp.cl/articulos/carlos_pizarro/Responsabilidadcontractualenderechochileno (fecha de descarga 23 de junio de 2012)>.

Pothier, Robert (2007): Tratado de las obligaciones (Buenos Aires, Editorial Bibliográfica Argentina) pp. 573.

Puig Peña, Federico (1976): Compendio de Derecho Civil español (Madrid, Pirámide) pp. 400.

Ramos Pazos, René (2004): De las obligaciones (Santiago, LexisNexis) pp. 571.

Rodríguez Grez, Pablo (2003): Responsabilidad contractual (Santiago, Editorial Jurídica de Chile) pp. 337.

Rodríguez Guitián, Alma (2008): "La reparación del daño moral en la contratación inmobiliaria”, Revista de Derecho N 30, pp. 141-163.

Salinas Ugarte, Gastón (2011): Responsabilidad civil contractual (Santiago, Abedelo Perrot) pp. 1003.

SolÉ Feliú, Josep (2009): "El daño moral por infracción contractual: principios, modelos y derecho español", InDret, Revista para el Análisis del Derecho, pp. 1-42.

Somarriva Undurraga, Manuel (1984): Las obligaciones y los contratos ante la jurisprudencia (Santiago, Editorial Jurídica de Chile, segunda edición actualizada) pp. 422.

Tapia SuÁrez, Orlando (2007): De la responsabilidad civil en general y de la responsabilidad delictual entre los contratantes (Santiago, LexisNexis, segunda edición actualizada) pp. 654.

Tomasello Hart, Leslie (1969): El daño moral en la responsabilidad contractual (Santiago, Editorial Jurídica de Chile) pp. 505.

Valverde-Valverde, Calixto (1937): Tratado de derecho civil español (Valladolid, Talleres Tipográficos) pp. 843.

Vergara Bezanilla, José Pablo (2000): "La mercantilización del daño moral”, Revista de Derecho del Consejo de Defensa del Estado, Año 1, No 1, pp. 70 y ss.

Vodanovic H., Antonio (1979): Derecho de las obligaciones (Santiago, Ediciones Periodísticas y Estadísticas) pp. 176.

Yzquierdo Tolsada, Mariano (1993): La responsabilidad civil contractual y extracontractual (Madrid, Editorial Reus) pp. 286. 
